\title{
FENOMENA BAHASA PADA RUANG PUBLIK SEPANJANG JALAN PROTOKOL KOTA PONTIANAK
}

\author{
PHENOMENON OF THE LANGUAGE IN THE PUBLIC ROOM \\ AROUND PROTOCOL STREET PONTIANAK CITY
}

\author{
Wahyu Damayanti \\ Balai Bahasa Kalimantan Barat \\ wahyu_b7320@yahoo.com
}

Naskah diterima tanggal 11 September 2019

Naskah direvisi terakhir tanggal 8 Desember 2019

\begin{abstract}
The priority of the country's language becomes a reflection that the city upholds Indonesian language. This does not rule out the possibility of the Pontianak city government. This paper tries to explain the phenomenon of language in public spaces along the Pontianak city protocol. The aim is to describe the use of language and find out the level of language control in Pontianak city public spaces. This research method uses a combination of quantitative methods and qualitative methods. Quantitative method is used as a method of processing the number of population and corpus of data to determine the number of data samples. The qualitative method is used as a method of analyzing the linguistic features of data samples which include the type of language landscape and language use of data samples. The data source of this research is the primary data source directly collected directly from the area along the Pontianak city protocol streets. Data were classified and analyzed according to the study. Data analysis in this study was presented using descriptive analytic methods. The results of the study are the existence of language shifts that can be seen from the emergence of complete foreign language interference, grammatical interference, the use of foreign terms in the structure of language and code-switching in foreign language. The level of language control along the protocol road in the public sphere has a significant result, $B$, which means that the state language is still controlled at the level of public space.
\end{abstract}

Keywords: phenomenon, language, public space, pontianak

\begin{abstract}
Abstrak
Pengutamaan bahasa negara menjadi cerminan bahwa kota tersebut menjunjung tinggi bahasa Indonesia. Hal ini tidak menutup kemungkinan dilakukan oleh pemerintah kota Pontianak. Tulisan ini mencoba memaparkan fenomena bahasa pada ruang publik di sepanjang jalan protokol kota Pontianak. Tujuannya adalah mendiskripkan penggunaan bahasa dan mengetahui tingkat keterkendalian bahasa pada ruang publik kota Pontianak. Metode penelitian ini menggunakan kombinasi antara metode kuantitatif an metode kualitatif. Metode kuantitatif digunakan sebagai metode pengolahan jumlah populasi dan korpus data hingga penentuan jumlah sampel data. Metode kualitatif digunakan sebagai metode analisis fitur linguistik dari sampel data yang meliputi jenis lanskap bahasa dan penggunaan bahasa dari sampel data. Sumber data penelitian ini adalah sumber data primer yang langsung dikumpulkan langsung dari kawasan sepanjang jalan-jalan protokol kota Pontianak. Data diklasifikasi dan dianalisis sesuai dengan kajian. Analisis data dalam penelitian ini dipaparkan dengan menggunakan metode deskriptif analitik. Hasil kajian adalah adanya pergeseran bahasa yang dapat dilihat dari munculnya interferensi bahasa asing secara utuh, interferensi ketatabahasaan, penggunaan istilah asing dalam struktur bahasa dan campur kode bahasa asing. Tingkat keterkendalian bahasa di sepanjang jalan protokol pada ruang publik memperoleh hasil yang signifikan yaitu $\mathrm{B}$, yang berarti bahasa negara masih terkontrol pada tataran ruang publik.
\end{abstract}


Kata-kata kunci: fenomena, bahasa, ruang publik, pontianak

\section{PENDAHULUAN}

Kota Pontianak adalah ibukota provinsi Kalimantan Barat yang notabene masyarakatnya multietnis. Selain multietnis Kalimantan Barat juga sebagai tempat persinggahan warga asing khususnya warga Malaysia karena negara tetangga yang sangat dekat, tidak menutup kemungkinan warga asing lainnya. Multietnis menjadikan Kalimantan Barat memiliki berbagai suku bahasa.

Berbicara kota Pontianak sebagai ibukota provinsi tentunya modal kuat dalam perekonomian di wilayah Kalimantan Barat. Perekonomian kuat dengan masuknya investor luar ke kota Pontianak dibuktikan dengan makin maraknya pusat-pusat perbelanjaan seperti Mega Mall, Transmart Studio, Mitra Mart, dan hotel-hotel bintang lima. Sebagai ibukota provinsi kota Pontianak merupakan persinggahan pertama bagi warga luar Pontianak maupun warga asing jika melalui udara, sehingga pendatang baru akan lebih dulu melihat dan merasakan situasi kota Pontianak. Dengan banyaknya wisatawan mancanegara yang datang ke kota Pontianak, maka makin menjamur pula hotel-hotel di kota Pontianak sebagai sarana akomodasi mereka.

Seiring dengan perkembangan pesat kota Pontianak beriring juga perkembangan penggunaan bahasa di ruang publik. Fenomena yang ada saat ini, penggunaan bahasa asing masih melekat di ruang publik meski tidak banyak. Hal ini dapat dilihat penamaan hotel di sepanjang jalan protokol kota Pontianak masih menggunakan kaidah bahasa asing seperti Mercure Hotel, Ibis Hotel, Mahkota Hotel dan masih banyak lagi.

Dari fenomena yang ada sebagian besar penggunaan bahasa asing dilakukan oleh pihak swasta yang notebennya penyumbang pajak terbesar kepada pemerintah daerah. Hal ini sangat bertentangan sekali dengan surat edaran Gubernur Kalimantan Barat tertanggal 30 Januari 2019 nomor 085/0384/OR-B tentang Pengutamaan Bahasa Negara di Ruang
Publik. Surat edaran tersebut bukan hanya di atas kertas, namun menjadikan tugas besar pemerintah daerah Kalimantan Barat untuk menindaklanjuti secara aksi guna penertiban penggunaan bahasa di tempat umum atau ruang publik karena masih banyaknya kasus pelanggaran dalam penggunaan bahasa asing atau bahasa yang tidak taat kaidah bahasa Indonesia.

Menurut Halim dalam Syahrul (2018) menyatakan bahwa salah satu faktor yang memengaruhi kelancaran dan keberhasilan pelaksanaan kebijakan bahasa nasional adalah sikap bahasa yang dimiliki oleh warga masyarakat yang bersangkutan (hlm. 176). Hambatan yang berkaitan dengan sikap bahasa dalam rangka mempertahankan bahasa Indonesia sebagai jati diri bangsa, dapat diketahui dari beberapa pendapat para ahli dan pengamat bahasa sebagai berikut.

Alwi (2011) berpendapat bahwa masalah bahasa di Indonesia memperlihatkan ciri yang sangat kompleks (hlm. 6) . Hal itu berkaitan erat dengan tiga aspek, yaitu yang menyangkut bahasa, pemakai bahasa, dan pemakaian bahasa. Aspek bahasa menyangkut bahasa Indonesia, bahasa daerah, dan bahasa asing (terutama bahasa Inggris). Aspek pemakai bahasa terutama berkaitan dengan mutu dan keterampilan berbahasa seseorang. Dalam perilaku berbahasa tidak saja terlihat mutu dan keterampilan berbahasa, tetapi juga sekaligus dapat diamati apa yang sering disebut sebagai sikap pemakai bahasa terhadap bahasa yang digunakannya. Adapun aspek pemakaian bahasa mengacu pada bidang-bidang kehidupan yang merupakan ranah pemakaian bahasa.

Kridalaksana (1980) menyebutkan bahwa orang Indonesia cenderung bersikap tidak menghargai bahasanya karena lebih bangga menggunakan bahasa asing. Begitu juga menurut Manurung (2018) kecenderungan dan perilaku untuk mencampuradukan bahasa asing ke dalam bahasa Indonesia bukan hanya dilakukan oleh kelompok, badan, atau lembaga saja, tetapi sudah dilakukan oleh perseorangan. Hal ini 
sangat membahayakan eksistensi jati diri bangsa (hlm. 240).

Penggunaan bahasa Indonesia yang sudah terinterferensi oleh bahasa asing harus ditanggulangi. Jika dibiarkan akan menyudutkan bahasa Indonesia. Saatnya kita melakukan pemurnian bahasa Indonesia dan mencegah adanya interferensi bahasa asing di ruang publik.

Berdasarkan latar belakang tersebut, penulis melakukan kajian mengenai bagaimana penggunaan dan tingkat keterkendalian bahasa pada ruang publik di sepanjang jalan protokol kota Pontianak. Tujuan kajian ini mendiskripsikan penggunaan dan tingkat keterkendalian bahasa pada ruang publik di sepanjang jalan protokol kota Pontianak.

Manfaat penelitian ini secara praktis dan teori dapat dijadikan referensi penelitian selanjutnya yang berkaitan dengan fenomena penggunaan bahasa di ibukota provinsi khususnya untuk masyarakat Kalimantan Barat.

Penelitian yang relevan pernah dilakukan Hestiyana tentang "Penggunaan Bahasa pada Papan Nama di Ruang Publik Kabupaten Tanah Laut" tahun 2018, hasilnya terdapat kesalahan dalam penggunaan bahasa antara lain: 1) ejaan, yang mencakup (a) pemakaian huruf kapital; (b) penulisan kata yang mencakup penulisan kata depan, serta penulisan singkatan dan akronim; serta (c) pemakaian tanda baca yang mencakup tanda titik, tanda koma, dan tanda hubung; (2) bentuk dan pilihan kata; 3) pengaruh bahasa asing.

Penelitian lainnya dilakukan oleh Arum Jayanti (2018) berjudul "Variasi Lanskap Bahasa Ruang Publik di Yogyakarta". Hasil penelitian tersebut diantaranya variasi lanskap bahasa pada ruang publik di Yogyakarta terdiri atas delapan jenis, yaitu (1) bahasa Indonesia, (2) bahasa Jawa, (3) bahasa Inggris, (4) bahasa asing lainnya, (5) bahasa Indonesia dan bahasa Jawa, (6) bahasa Indonesia dan bahasa Inggris, (7) bahasa Jawa dan bahasa Inggris, (8) bahasa Inggris dan bahasa asing lainnya.
Perbedaan dengan penelitian ini bahwa penelitian ini melihat fenomena bahasa yang ada di jalan protokol Kota Pontianak lebih memfokuskan pengutamaan bahasa negara dengan mengukur tingkat keterkendalian bahasanya di ruang publik.

\section{LANDASAN TEORI}

Menurut HP dan Abdullah (2012) konsep kedwibahasaan muncul karena ada situasi yang dikenal sebagai kontak bahasa. Kontak bahasa ini secara sederhana didefinisikan sebagai proses saling pengaruh antara berbagai bahasa, dialek, ataupun variasi yang terjadi akibat adanya interaksi antara para pengguna bahasa (hlm. 159).

Di sisi lain, Hoffman (1994) menggambarkan bilingualisme sebagai konsep yang relatif dengan sejumlah definisi, tetapi tidak ada satu pun yang berteriman denga tepat. Ia mengungkapkan lebih lanjut agar pembahasan bilingualisme dikaitkan dengan aspek-aspek yang berkesesuaian dengan kebutuhan penentuan profil bilingual itu sendiri, misalnya pemerolehan bahasa, kemampuan bahasa, fitur-fitur linguistik, dan sikap bahasa. Alur yang disampaikan Hoffman memunculkan konsep bilingualisme Bloomfield (1976) yang mengungkapkan bahwa bilingualisme adalah gejala penguasaan bahasa kedua (B2) dengan derajat kemampuan yang sama dengan penutur aslinya. Akan tetapi, ia menegaskan bahwa tidak semua orang yang selalu berganti-ganti bahasa dapat disebut sebagai bilingual/dwibahasawan.

Pokok pikiran Bloomfiel ini kemudian dikembangkan oleh Weinreich (1968). Menurutnya, bilingualisme merupakan kebiasaan seorang penutur untuk menggunakan satu bahasa lalu beralih ke bahasa yang lain. Bahasa-bahasa yang berada dalam kondisi demikian ini dikategorikannya ke dalam kondisi saling kontak, sedangkan individu (penutur) yang terlibat di dalamnya disebutnya sebagai bilingual (dwibahasawan).

Masyarakat dwibahasawan atau aneka bahasawan secara sengaja atau tidak sengaja cenderung menggunakan dua bahasa atau 
lebih dalam satu percakapan. Kecenderungan itu diantaranya untuk mempertegas, meminta, membahas, membujuk, merayu, atau mengklasifikasi percakapan. Gejala yang semacam ini merupakan gejala yang sangat umum dalam masyarakat dwibahasawan.

Dari beberapa pendapat tentang kedwibahasawan tersebut dapatlah disimpulkan bahwa kedwibahasawan adalah ciri khas penggunaan bahasa dan bukan fenomena bahasa. Kedwibahasawan merupakan ciri pesan seseorang yang terlahir dalam penggunaan dua bahasa atau lebih ddalam kehidupan sehari-hari.

Namun di sisi lain, adanya regulasi pemerintah kita untuk dapat melaksanakan amanat Undang-Undang Nomor 24 Tahun 2009 tentang Bahasa Indonesia. Di dalam Undang-Undang Nomor 24 Tahun 2009 Pasal 38 ayat (1) dalam undang-undang diatur bahwa bahasa Indonesia wajib digunakan dalam rambu umu, penunjuk jalan, fasilitas umum, spanduk, dan alat informasi lainnya yang merupakan pelayanan umum. Selanjutnya, pada ayat (2) pasal tersebut diatur bahwa penggunaan bahasa Indonesia sebagaimana dimaksud pada ayat (1) dapat disertai bahasa daerah atau bahasa asing jika dipandang perlu. Ketentuan lebih lanjut mengenai penggunaan bahasa Indonesia sebagaimana yang dimaksuddalam undangundang diatur dalam Peraturan Presiden.

Kemudian dalam Surat edaran Gubernur Kalimantan Barat tertanggal 30 Januari 2019 nomor 085/0384/OR-B tentang Pengutamaan Bahasa Negara di Ruang Publik. Salah satu poin yang tercantum dalam surat edaran tersebut adalah mewajibkan pengutamaan Bahasa Indonesia pada lima objek ruang publik, yaitu :

1. nama lembaga dan gedung;

2. nama bangunan, jalan, apartemen atau pemukiman, perkantoran, komplek perdagangan, merek dagang, lembaga usaha dan lembaga pendidikan;

3. petunjuk jalan, fasilitas umum, spanduk dan alat informasi lain merupakan pelayanan umum;

4. nama ruang pertemuan;
5. nama dan informasi produk barang/jasa.

Surat edaran Gubernur Kalimantan Barat merupakan perpanjangan tangan dari imbauan Menteri Dalam Negeri Nomor 40 Tahun 2007 tentang Pedoman bagi Kepala Daerah dalam pelestarian dan pengembangan Bahasa Negara dan surat Ombudsman RI Nomor 1710/ORI-STR/IX/2018 untuk melakukan pengawasan atau pelayanan publik yang diberikan oleh penyelenggara negara dan pemerintahan.

\section{METODE PENELITIAN}

Metode penelitian ini menggunakan kombinasi antara metode kuantitatif an metode kualitatif. Metode kuantitatif digunakan sebagai metode pengolahan jumlah populasi dan korpus data hingga penentuan jumlah sampel data. Metode kualitatif digunakan sebagai metode analisis fitur linguistik dari sampel data yang meliputi jenis lanskap bahasa dan penggunaan bahasa dari sampel data.

Sumber data penelitian ini adalah sumber data primer yang langsung dikumpulkan langsung dari kawasan sepanjang jalan-jalan protokol kota Pontianak. Sumber data adalah foto langsung lanskap bahasa yang terdapat di kawasan jalan protokol Kota Pontianak. Data penelitian ini berupa penggunaan kata-kata lanskap bahasa di kawasan jalan protokol Kota Pontianak.

Teknik pengumpulan data menggunakan teknik dokumentasi dengan alat kamera. Data diklasifikasi menurut jenisnya, yaitu papan nama instansi pemerintah dan swasta, papan nama pusat atau tempat perdagangan, iklan luar ruang, dan papan nama tempat pemukiman atau penginapan, serta petunjuk lalu lintas dan pariwisata. Analisis data dalam penelitian ini dipaparkan dengan menggunakan metode deskriptif analitik.

Pengolahan Data

a. Seratus data pengutamaan penggunaan bahasa dikodifikasi sesuai dengan petunjuk kodifikasi. 
b. Data dinilai sesuai dengan kaidah penilaian yang telah ditentukan dalam instrumen penilaian.

c. Data ditabulasikan ke dalam tabel aplikasi instrumen hingga menghasilkan peringkat keterkendalian untuk wilayah

Peringkat Keterkendalian

Berikut ini kriteria peringkat keterkendalian wilayah kota/kabupaten berdasarkan tiga variabel kebahasaan.

\section{Tabel 1}

Peringkat Keterkendalian

\begin{tabular}{|c|c|c|c|c|}
\hline \multirow{2}{*}{$\begin{array}{c}\text { Ter } \\
\text { ken } \\
\text { dali }\end{array}$} & \multirow{2}{*}{ Rentang } & \multicolumn{3}{|c|}{ Kebahasaan } \\
\cline { 3 - 5 } & & Fisik & $\begin{array}{c}\text { Kai } \\
\text { dah }\end{array}$ & $\begin{array}{c}\text { Tipo } \\
\text { grafi }\end{array}$ \\
\hline A & $2.601-3.000$ & ++ & ++ & ++ \\
\hline B & $2.201-2.600$ & + & + & + \\
\hline C & $1.800-2.200$ & - & + & + \\
\hline D & $1.400-1.799$ & - & - & - \\
\hline
\end{tabular}

(Sumber: Juknis Badan Pengembangan dan Pembinaan Bahasa, Kemdikbud 2018)

Catatan:

Skor < 1.399 dikualifikasi dalam kategori belum terkendali.

Untuk penilaian setiap data menggunakan tabel penilaian dengan jumlah objek dan kodifikasi data yang digunakan berjumlah 100 objek dalam satu format penilaian untuk satu wilayah penggunaan bahasa.

Deskripsi Peringkat Keterkendalian

Terkendali A

Kategori ini menunjukkan wilayah yang penggunaan bahasa di ruang publiknya sangat terkendali: secara fisik tidak ditemukan bahasa asing; sepenuhnya berbahasa negara dengan penerapan kaidah dan tipografi yang sangat baik.

Terkendali B
Kategori ini menunjukkan wilayah yang penggunaan bahasa di ruang publiknya cukup terkendali: secara fisik tidak didominasi bahasa asing; jauh lebih banyak berbahasa negara dengan penerapan kaidah dan tipografi yang makin baik.

Terkendali C

Kategori ini menunjukkan wilayah yang penggunaan bahasa di ruang publiknya kurang terkendali: secara fisik kurang didominasi bahasa asing; mulai lebih banyak berbahasa negara dengan penerapan kaidah dan tipografi yang mulai baik.

Terkendali D

Kategori ini menunjukkan wilayah yang penggunaan bahasa di ruang publiknya sangat kurang terkendali: secara fisik masih didominasi bahasa asing; sangat sedikit berbahasa negara dengan penerapan kaidah dan tipografi yang sangat kurang baik.

\section{PEMBAHASAN \\ Pergeseran Bahasa Negara}

Munculnya gejala penggunaan bahasa asing secara menyeluruh merupakan ancaman yang sangat bersar dan persoalan yang cukup serius bagi pemertahanan bahasa negara. Gejala pencampuran bahasa asing dalam bahasa negara lambat laun dapat menggeser kedudukan bahasa Indonesia. Adanya interferensi bahasa asing dapat mengancam keberadaan bahasa Indonesia.

Tidak dapat dipungkiri fenomena saat ini dalam komunikasi sehari-hari, bahasa asing sudah menjadi bahasa sehari-hari masyarakat Indonesia, meski masih ditemui pada komunitas tertentu. Hal ini dilakukan karena bagi sebagian besar masyarakat beranggapan bahwa bahasa asing lebih bergengsi dan berkelas. Dengan penggunaan istilah-istilah asing mereka lebih berprestise dan lebih bergaya, dibandingkan dengan bahasa negaranya. Faktor penyebab lain, selain beberapa hal yang telah dipaparkan di atas, masyarakat kita biasanya merasa bahwa mereka tidak mengetahui padanan kata atau istilah dalam bahasa Indonesia. Sementara itu, mereka beranggapan bahwa tidak semua 
ungkapan atau istilah bahasa asing tepat digunakan dalam bahasa Indonesia.

Pada hakikatnya, bahasa Indonesia memiliki banyak kekayaan kosa kata yang tepat dan komunikatif, tetapi tidak semua kosa kata belum banyak disosialisaikan ke masyarakat. Tugas masyarakat Indonesia tidak hanya berdiam diri dengan adanya pergeseran bahasa negara, dengan tetap mempertahankan bahasa dan menjadikan bahasa negara menjadi tuan rumah di negeri sendiri.

\section{Munculnya Interferensi Bahasa Asing di Ruang Publik}

Menurut Kridalaksana (2001) interferensi bahasa adalah penggunaan unsur bahasa lain oleh bahasawan yang bilingual secara individual dalam suatu bahasa; ciri-ciri bahasa lain masih kentara. Dominasi bahasa asing di ruang publik hendaknya kita cegah lebih dini, sebelum bahasa asing tersebut menjajah negeri ini. Penggunaan bahasa asing di ruang publik dan bisnis umumnya terjadi karena pelaku bisnis ingin meningkatkan citra dan pesona untuk menarik konsumen, kelas sosial dan kesempurnaan sebuah perusahaan akan terangkat.

Bahasa negara pun tidak kalah dengan bahasa asing, dapat menfasilitasi tingkat pemahaman pembacanya di ruang publik diantaranya sains, teknologi, budaya, dan seni. Meski banyak anggapan bahwa bahasa asing lebih kekinian, namun sebagai penutur bahasa negara dapat meminimalisir penggunaan bahasa asing.

\section{Interferensi Bahasa Asing Utuh}

Pelaku bisnis kerap menggunakan bahasa asing banyak ditemukan pada ruang publik di kota Pontianak. Untuk data (1) adanya intereferensi bahasa asing secara utuh.

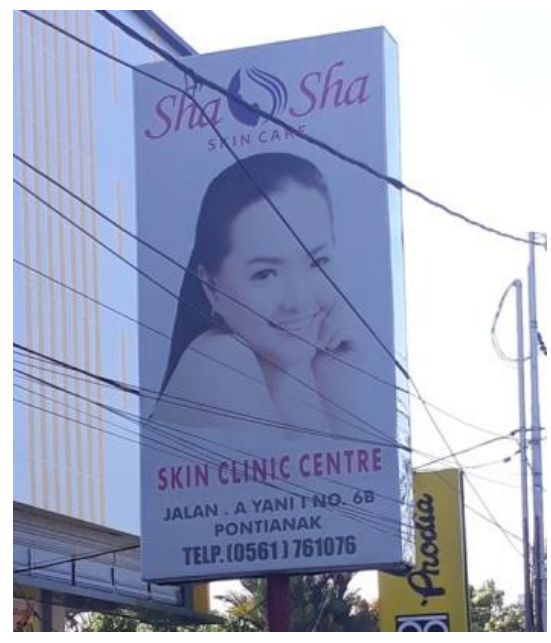

Data (1) merupakan penggunaan bahasa asing utuh di sekitaran jalan Ahmad Yani Pontianak. Papan nama swasta dengan hanya menggunakan bahasa asing seperti SHA SHA SKIN CARE, SKIN CLINIC CENTER. Data tersebut merupakan papan nama klinik yang menawarkan jasa perawatan kecantikan kulit, nama produknya Sha Sha. Hal ini dapat membuktikan bahwa interferensi bahasa asing yang digunakan secara utuh di ruang publik sepanjang jalan protokol kota Pontianak sangat disayangkan. Alangkah baiknya papan nama tersebut diganti menjadi Perawatan Kulit Sha Sha, Pusat Klinik Perawatan Kulit, di bawahnya diikuti bahasa asing. Sehingga bahasa asing bukan yang dominan dalam papan nama tersebut.

Perhatikan data (2) yang juga menggunakan kata asing yang utuh pada kain rentang untuk menawarkan produk olahan kuliner. 


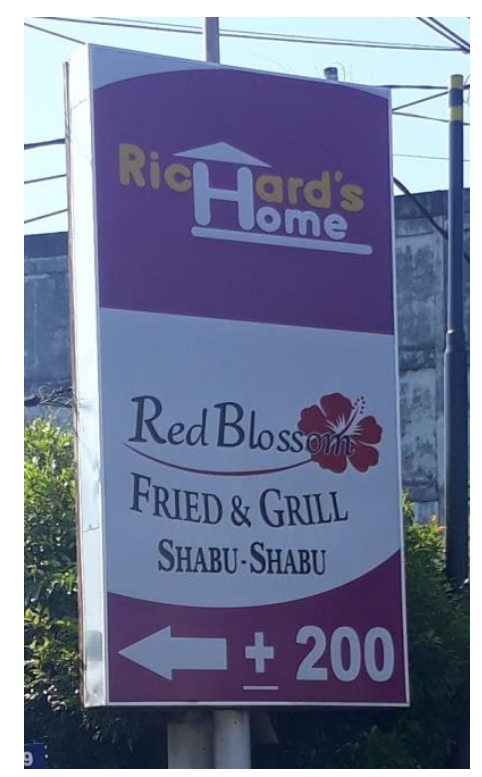

Data (2) menyajikan produk kuliner shabu-shabu ini terpampang jelas di sekitaran jalan Ahmad Yani yang merupakan jalan protokol bagi pengguna jalan masyarakat Pontianak. Richard's Home merupakan nama rumah makan yang menjual hasil olahan dengan cara digoreng, dipanggang dan olahan shabu-shabu. Rumah makan ini baru berdiri sehingga belum banyak konsumen kuliner yang tahu keberadaannya. Hal ini yang menjadi alasan pemilik rumah makan menggunakan bahasa asing, agar lebih keren dan bergengsi bagi konsumen.

Keutuhan penggunaan bahasa asing ini yang justru menjadikan bahasa Indonesia tergeser secara perlahan. Kalau hanya sekadar nama produk karena nama produk merupakan nilai jual bagi konsumen agar mudah diingat, mungkin masih bisa ditolerir. Namun pada kain rentang tersebut hasil olahan kulinernya juga menggunakan bahasa asing yang belum tentu konsumen mengerti akan arti kuliner tersebut menjadikan konsumen malah bertanya-tanya apa saja yang ditawarkan oleh rumah makan tersebut.

\section{Interferensi Tatanan Kebahasaan}

Pada hakikatnya, hukum atau prinsip kebahasaan dalam bahasa Indonesia ialah hukum DM (Diterangkan- Menerangkan). Artinya, kata pertama dalam frasa adalah inti dan kata kedua atau kata berikutnya adalah penjelas.
Berikut data (3) yang menggunakan interferensi tatanan kebahasaan asing.

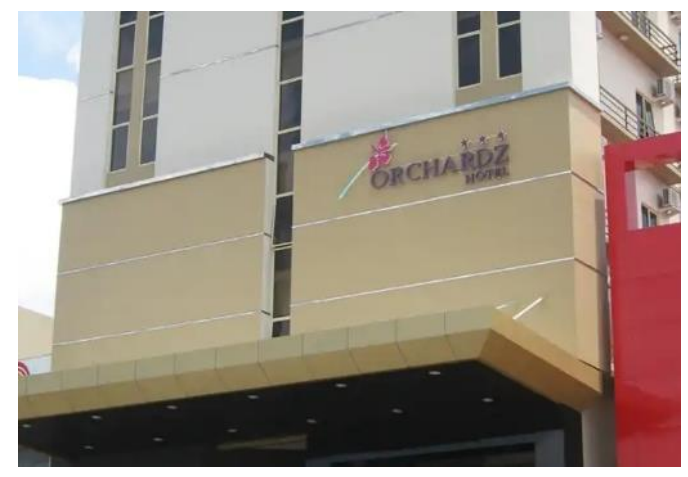

Nama hotel pada data tersebut yaitu Orchardz Hotel. Tatanan kebahasan menggunakan pola bahasa asing yaitu MD (Menerangkan-Diterangkan). Jika menggunakan tatanan kebahasaan bahasa Indonesia harusnya DM, sehingga papan nama hotel yang tepat adalah Hotel Orchardz.

Untuk data (4) berikut ini mempunyai kasus yang sama dengan data sebelumnya.

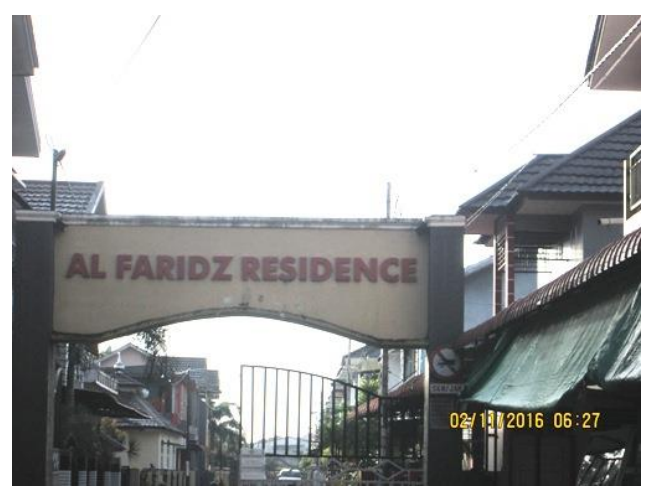

Hal ini juga ditemukan pada penamaan komplek perumahan di sekitar jalan protokol tepatnya di jalan Sepakat 2, Ahmad Yani, Pontianak. Penamaan Al Faridz Residence merupakan tatanan kebahasaan bahasa asing M-D (Menerangkan dan Diterangkan). Kata residence merupakan bahasa Inggris yang berarti tempat tinggal atau perumahan. Oleh karena itu, penulisan yang tepat pada data tersebut dengan menggunakan prinsip kebahasaan dalam bahasa Indonesia yaitu DM (DiterangkanMenerangkan) menjadi Perumahan Al Faridz. Fenomena seperti ini tidak hanya ditemukan pada penamaan hotel dan perumahan saja, namun hampir di semua fasilitas masyarakat 
Pontianak di sepanjang jalan protokol Pontianak.

\section{Penggunaan Istilah Asing dengan Struktur Bahasa Asing}

Penulisan istilah asing juga ditemukan pada papan nama dagang di sepanjang jalan protokol kota Pontianak. Terdapat dua data yang ditulis secara bahasa asing yaitu Laundry Fresco dan Rose's Salon.

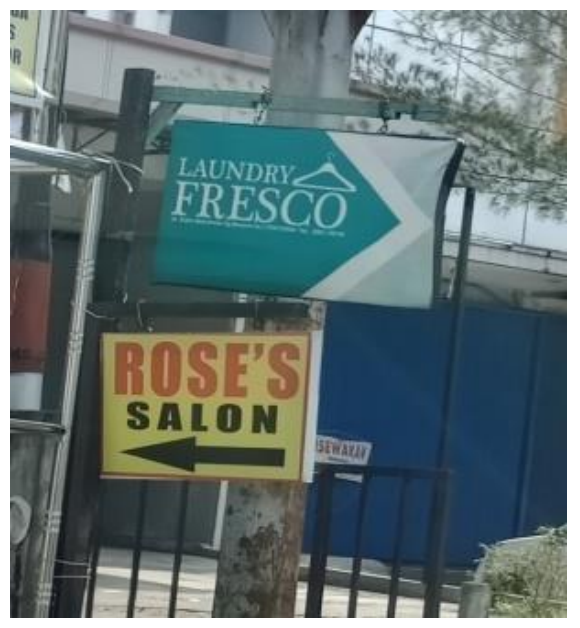

Data tersebut menjadi bukti bahwa penulisan istilah asing atau dalam bentuk asing benar-benar sudah menjamur dan dianggap masyarakat sudah benar. Kata Laundry sudah memiliki padanan kata dalam bahasa Indonesia yaitu Binatu. Pada papan nama Laundry Fresco merupakan jasa penatu (KBBI daring) yang artinya usaha atau orang yang bergerak di bidang pencucian (penyeterikaan) pakaian dengan nama produk Fresco. Sehingga penulisan dalam bahasa Indonesia sebaiknya Penatu Fresco, jika ingin dicantumkan bahasa asing setelah bahasa Indonesia bisa diikuti bahasa asing.

Data (5) pada penulisan Rose's Salon menggunakan bahasa asing yang berarti salon milik rose. Penulisan sesuai bahasa Indonesia yaitu Salon Rose yang berarti salon yang bernama atau kepemilikan Rose.

Berikut data (6) pada nama gedung yang menggunakan istilah asing dengan struktur bahasa asing. 


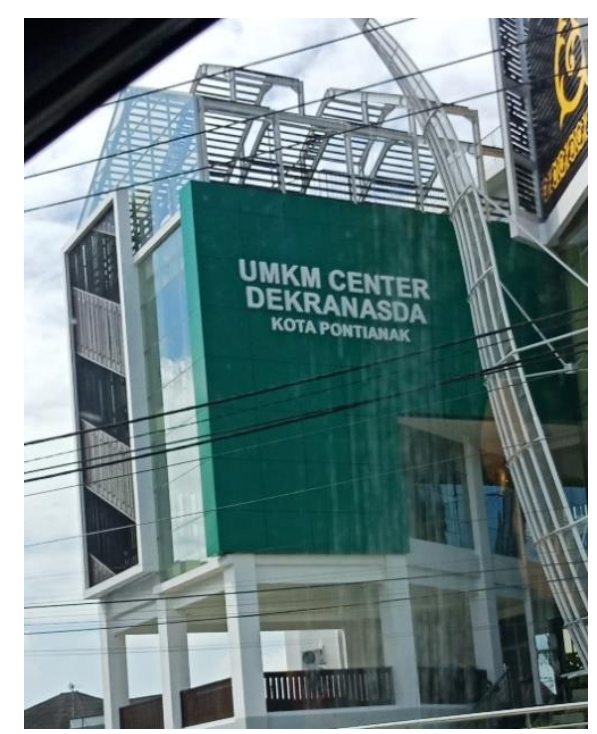

Campur kode tidak hanya ditemukan pada komunikasi verbal namun hal ini ditemukan dalam bentuk tulisan.

Penulisan kata Center di tengah antara kata UMKM dan Deskranasda merupakan unsur campur kode bahasa asing yang muncul.

Munculnya kata asing di tengah-tengah bahasa Indonesia pada papan nama gedung instansi pemerintah tidak tepat, hal ini yang merusak martabat bahasa Indonesia. Meskipun tujuannya hanya ingin mendongkrak agar lebih trendi diantara papan nama instansi lainnya malah menjadi salah kaprah dalam penggunaannya. Penulisan yang tepat nama gedung jika ingin menggunakan bahasa asing bisa diletakkan di bawah setelah penulisan bahasa Indonesia. Jadi perbaikan penulisan nama gedung tersebut adalah Pusat UMKM Dekranasda Pontianak.

Di bawah ini data yang juga menggunakan unsur campur kode. Kain rentang yang bertuliskan promosi sebuah produk kuliner ditemukan di sekitaran jalan Ahmad Yani, jalan utama masyarakat Pontianak melewati jalan ini.

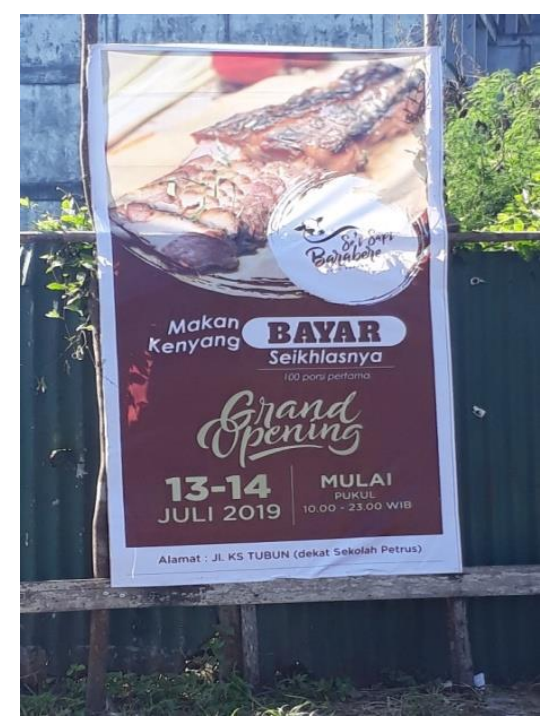

Pada kain rentang tersebut tercantum kata Grand Opening yang berarti Pembukaan Besar. Campur kode pada kain rentang tersebut dengan mencantumkan bahasa asing yang sudah menjamur di Kota Pontianak. Biasanya kata Grand Opening ini untuk tokotoko, gerai, perusahaan atau hotel yang akan memperkenalkan produknya kepada khalayak ramai, dalam hal ini masyarakat di sekitaran Kota Pontianak.

Alangkah baiknya penulisan tersebut diganti menjadi Pembukaan Besar, meski bagi masyarakat umum sangat janggal, namun kalau sudah terbiasa dengan hal-hal yang benar lama-lama akan menjadi wajar.

\section{Tingkat Keterkendalian Bahasa pada} Ruang Publik Kota Pontianak

Jika ditilik dari beberapa sampel yang diambil yaitu seratus sampel terdiri dari 15 dari papan nama intansi pemerintah dan swasta, 15 dari papan nama dagang (pusat perdagangan), 20 data dari iklan komersil, 10 data dari baliho (yang bersifat imbauan atau pengumuman), 15 data dari nama restoran, 15 data papan nama perumahan dan perhotelan, dan 10 data dari penunjuk arah (ramburambu) lalu lintas dan nama tempat pariwisata. Hasilnya menunjukkan bahwa kota Pontianak memperoleh kriteria tingkat keterkendalian B dengan nilai 2550, berarti bahwa wilayah yang penggunaan bahasa di ruang publiknya cukup terkendali: secara fisik tidak didominasi bahasa asing; lebih banyak 
berbahasa negara dengan penerapan kaidah dan tipografi yang makin baik.

Meski masih banyak ditemukan bahasa asing di sepanjang jalan protokol, namun tidak mendominasi bahasa negara. Hasil yang cukup signifikan diantara tingkat kompetisi bahasa yang digunakan khususnya pelaku bisnis yang lebih mengejar keuntungan dibandingkan ketaatan dalam kebahasaan. Untuk instansi pemerintah masih dalam taraf menaati aturan kaidah bahasa, hal ini mungkin selain tingkat kesadaran yang cukup tinggi juga taat azas dari aturan pimpinan dengan memberikan sangsi hukum jika melanggar.

\section{PENUTUP}

\section{Simpulan}

Kota Pontianak sebagai ibukota provinsi memiliki komitmen dalam tatanan penggunaan bahasa negara yaitu bahasa Indonesia. Adanya pergeseran bahasa negara di ruang publik menjadikan kota Pontianak tetap menjadi kota yang menjunjung tinggi

\section{DAFTAR PUSTAKA}

Alwi, Hasan. (2011). Politik Bahasa. Jakarta: Pusat Bahasa.

Bloomfield, Leonard. (1976) Language. London: George Allen \& Unwin Ltd.

Hoffman, Charlotte. (1994). An Introduction to Bilingualism Dalam Applied Linguistics, Vol. 15/3 September.

HP, Achmad dan Abdullah, Alek. (2012). Linguistik Umum. Jakarta: Erlangga.

Jayanti, Arum. (2018). Variasi Lanskap Bahasa Ruang Publik di Yogyakarta. Dalam Makalah Seminar Dan Lokakarya Pengutamaan Bahasa Negara yang diselenggarakan Badan Pengembangan dan Pembinaan Bahasa, Kementerian Pendidikan dan Kebudayaan.

Kridalaksana, Harimurti. (1980). Fungsi dan Sikap Bahasa. Ende: Nusa Indah. (2001). Kamus Linguistik. Jakarta: Gramedia. martabat bahasa negara. Namun dari beberapa data dalam kajian ini pergeseran bahasa dapat dilihat dari munculnya interferensi bahasa asing secara utuh, interferensi ketatabahasaan, penggunaan istilah asing dalam struktur bahasa dan unsur campur kode bahasa asing.

Tingkat keterkendalian bahasa di sepanjang jalan protokol pada ruang publik memperoleh hasil yang signifikan yaitu B, yang berarti bahasa negara masih terkontrol pada tataran ruang publik. Hasil yang cukup baik tidak menjadikan kota Pontianak merasa bangga dan terlena, justru menjadi cambuk untuk memperoleh nilai yang lebih baik ke tingkat A. Sehingga kota Pontianak akan menjadi kota yang menjunjung tinggi pemartabatan bahasa negara.

Ucapan terima kasih kepada peneliti Balai Bahasa Kalimantan Barat khususnya Ibu Martina, M. Pd. dan Ibu Amanah Hijriah, S.Pd. yang turut berkontribusi dalam penyelesaian makalah ini.

Manurung, T. Rosida. (2018). Interferensi Bahasa di Ruang Publik. Dalam Makalah Seminar Dan Lokakarya Pengutamaan Bahasa Negara yang diselenggarakan Badan Pengembangan dan Pembinaan Bahasa, Kementerian Pendidikan dan Kebudayaan.

Republik Indonesia. (2009). Undangundang tentang Bendera, Bahasa, dan Lambang negara, serta Lagu Kebangsaan. Jakarta: Kementerian Pendidikan dan Kebudayaan.

Pemda Kalbar. (2019). Surat Edaran Gubernur. Provinsi Kalimantan Barat.

Syahrul, Ninawati. (2018). Bahasa Ruang Publik: Representasi Jati Diri Bangsa. Dalam Makalah Seminar Dan Lokakarya Pengutamaan Bahasa Negara yang diselenggarakan Badan Pengembangan dan Pembinaan Bahasa, Kementerian Pendidikan dan Kebudayaan. 
Tim. (2018). Juknis Pengendalian Bahasa. Badan Pengembangan dan Pembinaan Bahasa, Kemdikbud.

Weinreich, Uriel. (1968). Language in Contact. The Hague: Mouton.

\section{Internet:}

Kamus Besar Bahasa Indonesia dalam jaringan diunduh tanggal 20 juli 2019 pkl.09.30. 